\title{
Análise da Evolução Temporal do Datum Vertical Brasileiro de Imbituba
}

\author{
Luciana Maria Da Silva* \\ Sílvio Rogério Correia de Freitas**
}

Recebido 9 de julho de 2018; aceito 17 de agosto de 2018

\begin{abstract}
Nowadays, the most central themes of Geodesy are linked to the provision of a unique Global Reference System, to which can be tied of unique form and with sufficient accuracy the geometrical and physical global changes. The Global Geodetic Reference Frame aims at better structuring Earth Observation Systems currently with prospects of the global changes determination at the level of one part per billion, considering several geometric and physical parameters. In this context, it is intended that the International Height Reference Frame, realization of the International Height Reference System, has an overall consistency of at least one centimeter in its realization and space/temporal control in the order of millimeter per year. Considering these aspects, it was analyzed the temporal evolution of the Imbituba Brazilian Vertical Datum utilizing tide gauge data from the sea level obtained from: Permanent Service for Mean Sea Level (1948 to 1968), University of Hawaii Sea Level Center (2001 to 2007) and Permanent Tide Gauge Network for Geodesy (2006 to 2016), and data from different altimetry missions from 1991 to 2015 obtained from the database of the Deutsches Geodätisches Forschungsinstitut. As like as, data obtained from GNSS continuous positioning of period from 2007 to 2016 from Brazilian GNSS Network for Continuous Monitoring, which were used to modeling the local movements of the crust. The results allowed discriminating the crust movements in relation to the sea

* Departamento de Geomática, Universidade Federal do Paraná. Centro de Estudos de Petróleo, Universidade Estadual de Campinas, e-mail: lumasilva15@gmail.com

** Departamento de Geomática, Universidade Federal do Paraná, Avenida Coronel Francisco H. dos Santos, 100 - Jardim das Américas, Curitiba-PR, e-mail: sfreitas@ufpr.br Os resultados apresentados neste trabalho foram advindos da Tese intitulada: "Análise da Evolução Temporal do Datum Vertical Brasileiro de Imbituba", defendida em 17 de fevereiro de 2017.
\end{abstract}


level. To achieve it, the trend of sea level variation evidenced by the tide gauge was used, as well as the variation of the vertical component obtained with the GNSS processing and the Sea Surface Height obtained from the satellite altimetry data.

Key words: Brazilian vertical datum, tide gauge, satellite altimetry, GNSS continuous data, mean sea level.

\section{Resumo}

Atualmente, os temas mais centrais da Geodésia vinculam-se ao provimento de um Sistema de Referência Global único, ao qual possam ser vinculadas de forma unívoca e com acurácia as mudanças globais de caráter geométrico e físico. O Global Geodetic Reference Frame visa a melhor estruturação dos Sistemas de Observação da Terra atualmente com perspectivas da determinação das mudanças globais ao nível de uma parte por bilhão, considerando vários parâmetros geométricos e físicos. Neste contexto pretende-se que o International Height Reference Frame, realização do International Height Reference System, possua consistência global de, pelo menos, um centímetro na sua realização e controle espaço/temporal na ordem do milímetro por ano. Considerando esses aspectos, analisou-se a evolução temporal do Datum Vertical Brasileiro de Imbituba utilizando dados maregráficos do nível do mar obtido de: Permanent Service for Mean Sea Level (1948 a 1968), University of Hawaii Sea Level Center (2001 a 2007) e Rede Maregráfica Permanente para Geodésia (2006 a 2016), e dados de distintas missões altimétricas do período de 1991 a 2015 obtidos do Banco de Dados do Deutsches Geodätisches Forschungsinstitut. Assim como, dados de posicionamento contínuo GNSS do período de 2007 a 2016, da Rede Brasileira de Monitoramento Contínuo, os quais foram utilizados para modelagem dos movimentos locais da crosta. Os resultados permitiram discriminar os movimentos da crosta em relação ao nível do mar. Para isto, utilizou-se a tendência de variação do nível do mar evidenciada pelo marégrafo, bem como a variação da componente vertical obtida com o processamento GNSS e da Sea Surface Height obtida dos dados dos satélites altímetros.

Palavras chave: Datum vertical brasileiro, marégrafo, altimetria por satélite, dados contínuos GNSS, nível médio do mar.

\section{Resumen}

Actualmente, los temas más centrales de Geodesia se vinculan a la provisión de un Sistema de Referencia Global único, al que puedan vincularse de forma unívoca y con exactitud los cambios globales de carácter geométrico y físico. El Global Geodetic Reference Frame tiene como objetivo la mejor estructuración de los Sistemas de Observación de la Tierra actualmente con perspectivas de la determinación de los cambios globales al nivel de una parte por mil millones, considerando varios parámetros geométricos y físicos. En este contexto, se pretende que el International 
Height Reference Frame, realizado por International Height Reference System, posea consistencia global de, por lo menos, un centímetro en su realización y control espacio/temporal en el orden del milímetro por año. Considerando estos aspectos, análisis y evolución temporal del Datum Vertical Brasileño de Imbituba utilizando datos mareográficos del nivel del mar de: Permanent Service for Mean Sea Level (1948 a 1968), University of Hawaii Sea Level Center (2001 a 2007) y Red Mareográfica Permanente para Geodésia (2006 a 2016), y datos de distintas misiones altimétricas del período 1991 a 2015 obtenidos del Banco de Datos del Deutsches Geodätisches Forschungsinstitut. Así como, datos de posicionamiento continuo GNSS del período de 2007 a 2016, de la Red Brasileña de Monitoreo Continuo, los cuales fueron utilizados para modelado de los movimientos locales de la corteza. Los resultados permitirán discriminar los movimientos de la corteza en relación al nivel del mar. Para esto, se utilizó la tendencia de variación del nivel del mar evidenciado por el mareógrafo, así como la variación del componente vertical obtenido con el procesamiento GNSS y de la Sea Surface Height obtenida de los datos de los satélites altimétricos.

Palabras clave: Datum vertical brasileño, mareógrafo, altimetría por satélite, dados continuos GNSS, nivel medio del mar.

\section{Demandas Globais para Referencial Vertical}

As mudanças no Sistema Terra têm como principais focos de análises, as redistribuições de massas observadas a partir da superfície ou do exterior da Terra, as quais se refletem principalmente nos aspectos geocinemáticos, nas variações do campo da gravidade e na rotação da Terra. Os quatro temas centrais do Global Geodetic Observing System (GGOS) relacionados com as mudanças globais são (GGOS, 2018): Theme 1 - Internacional Height Reference System (IHRS); Theme 2 - Geohazards Monitoring; Theme 3 - Sea Level Changes, Variability, and Forecasting; Theme 4 Geodetic Space Weather Research. O IHRS foi consolidado na Resolução ${ }^{\circ} 1$ da IAG em julho de 2015 (IAG, 2015) e sua realização global está sendo discutida no âmbito do GGOS (IAG, 2018). Um dos aspectos mais presentes nas discussões das mudanças globais é o associado à evolução do Nível Médio do Mar (NMM), principalmente quando se observa a evolução em áreas costeiras, em vista dos impactos diretos sobre as áreas que usualmente apresentam a maior concentração de ocupação humana. Tal aspecto é enfatizado em Smith et al. (2010).

Do ponto de vista geodésico e considerando principalmente os temas 1 e 3 do GGOS, há que se discutir os aspectos geocinemáticos da interação oceano-continente, fundamentais para a definição e realização de um Sistema Vertical de Referência (SVR) dentro de uma perspectiva de unicidade global (De Freitas, 2015; Da Silva et al., 2018). 
Em uma visão moderna, o Datum Vertical (DV) deve ser relacionado com uma referência global única, tal como previsto na Resolução ${ }^{\circ} 1$ da International Association Geodesy (IAG) que estabeleceu, em julho de 2015, o IHRS (IAG, 2015) baseado em um valor unívoco de geopotencial e que as coordenadas verticais primárias nas Redes Verticais de Referência (RVRs) sejam os números geopotenciais. A questão do valor unívoco foi discutida em Sánchez et al. (2012). As exigências atuais relativamente aos SVRs e RVRs têm sua fundamentação expressa principalmente nos pressupostos do GGOS.

O maior problema implícito relativamente aos Data Verticais (DVs) na atualidade é o do entendimento dos movimentos efetivos da crosta e do NMM discriminando movimentos eustáticos e tectônicos. A forma efetiva de discriminar esses movimentos é o monitoramento da posição geocêntrica dos marégrafos costeiros (De Freitas et al., 1998; Dalazoana et al., 2005; Da Silva et al.; 2016; Da Silva, 2017, Da Silva et al., 2018). Marégrafos instalados ao longo da linha de costa registram, portanto, os movimentos relativos do Nível do Mar (NM) e crosta, não discriminando os movimentos próprios de cada segmento. A integração dos dois segmentos pode ser melhor discriminada com a inserção de observações oriundas da altimetria por satélites (Bouman et al., 2010; CSIRO Marine and Atmospheric Research, 2018).

O Datum Vertical Brasileiro de Imbituba (DVB-I) e o Datum Vertical Brasileiro de Santana (DVB-S) foram estabelecidos dentro de um conceito clássico, onde se utiliza o NMM observado durante um certo período, adotando-se como a altitude de referência zero para redes altimétricas nacionais (Luz, 2008). Muitos países, assim como o Brasil, possuem mais de um DV em vista de impossibilidades físicas de conexão de todos os segmentos de suas redes altimétricas. Mais de uma centena de DVs são assim definidos e realizados em todo o mundo (De Freitas et al., 2002). O DVBI é referência nacional predominante, onde mais de $90 \%$ da Rede Vertical Fundamental do Brasil (RVFB) está a ele referenciada. Assim, as análises neste trabalho são centradas sobre o DVB-I.

Neste trabalho utilizaram-se séries temporais de posicionamento GNSS (Global Navigation Satellite System - Sistemas Globais de Navegação por Satélites) junto ao DVB-I. Estas séries de coordenadas geocêntricas são associadas então, com séries temporais de observações maregráficas e de observações advindas dos satélites altímetros, buscando-se determinar a evolução temporal do DVB-I no IHRS.

\section{Datum Vertical Brasileiro de Imbituba}

Segundo Dalazoana (2006), Luz (2008) e Da Silva (2017), a implantação da Rede Vertical Brasileira iniciou-se em 1945, em Santa Catarina, por meio de nivelamento 
geométrico. Sendo tomado como referência o Datum de Torres, com caráter provisório, pois o mesmo foi definido apenas com um ano de observações do nível do mar (1919-1920). Em 1949, o Inter-American Geodetic Survey (IAGS) iniciou a implantação da rede de estações maregráficas ao longo da costa brasileira.

Desde 1949 foram realizados diversos nivelamentos nas estações altimétricas que materializam o Datum de Imbituba. Em 1958, o Datum de Torres foi substituído pelo Datum de Imbituba, por possuir uma série temporal mais longa. Em 1959, foi então definido e adotado o Datum de Imbituba, através da promédia dos níveis médios do mar anuais, entre 1949 e 1957 (Alencar, 1990, p.70), no Porto de Imbituba, a partir do pressuposto que o NMM materializava o geoide.

A partir da década de 1980, com o advento das modernas técnicas espaciais, evidenciou-se que existem diferenças entre o NMM e o geoide, chamada de Topografia do NMM (TNMM). Diante dessa diferença, as altitudes passaram a apresentar inconsistências quando integradas às modernas técnicas baseadas em satélites artificiais. Em 1997, a Universidade Federal do Paraná (UFPR) em conjunto com o Instituto Brasileiro de Geografia e Estatística (IBGE) iniciou as distintas campanhas multiparamétricas na área do Datum, que seriam realizadas ao longo dos anos. Dentre elas destacam-se: posicionamento GPS, monitoramento da pressão atmosférica, marés terrestres e oceânicas, bem como a recuperação das referências altimétricas históricas, reativação da estação maregráfica, gravimetria e densificação de observações geodésicas na região contígua envolvendo o Sistema Lagunar de Imaruí e ainda a busca do vínculo da RVFB com o IHRS (Cordini, 1998; Dalazoana, 2006; Miranda, 2006; Luz, 2008; Ferreira, 2008; Luz et al., 2009; Palmeiro, 2011, Da Silva et al., 2016; Da Silva, 2017; Da Silva et al., 2018).

Dalazoana (2006) realizou um extenso trabalho de recuperação de vínculos entre níveis de referência no DVB-I, possibilitando a integração de novas observações com sensores modernos aos níveis de referência históricos. Palmeiro et al. (2013) trataram de diversas facetas da solução do PVCG nas formas livres e fixadas junto ao DVB-I. Estas são consequências dos distintos Níveis de Referência (NRs) envolvidos além das resoluções das diversas bases de dados utilizadas, conforme pode ser visto na Figura 1.

Tendo como consequências os distintos NRs e resoluções de diversas bases de dados, Palmeiro (2011) aplicou distintas técnicas na obtenção de soluções para as altitudes geoidais da estação de Imbituba (IMBI). As soluções foram obtidas a partir de MGGs, utilizando Colocação por Mínimos Quadrados (CMQ), e o Modelo de Ondulação Geoidal (MAPGEO 2010), atualmente já há uma atualização para 2015, o qual foi utilizado nesta pesquisa. Ressalta-se que a existência de distintas bases de dados, oriundas fontes, resoluções espaciais e referenciais distintos, é um problema na ideia de conexão da RVFB a um IHRS. Destaca-se que o estudo da compatibilidade de distintas fontes de dados, tais como observações maregráficas e altimetria 
por satélites, as quais refletem a superfície dinâmica dos oceanos, também devem ser consideradas, estes pontos foram considerados nesta pesquisa.

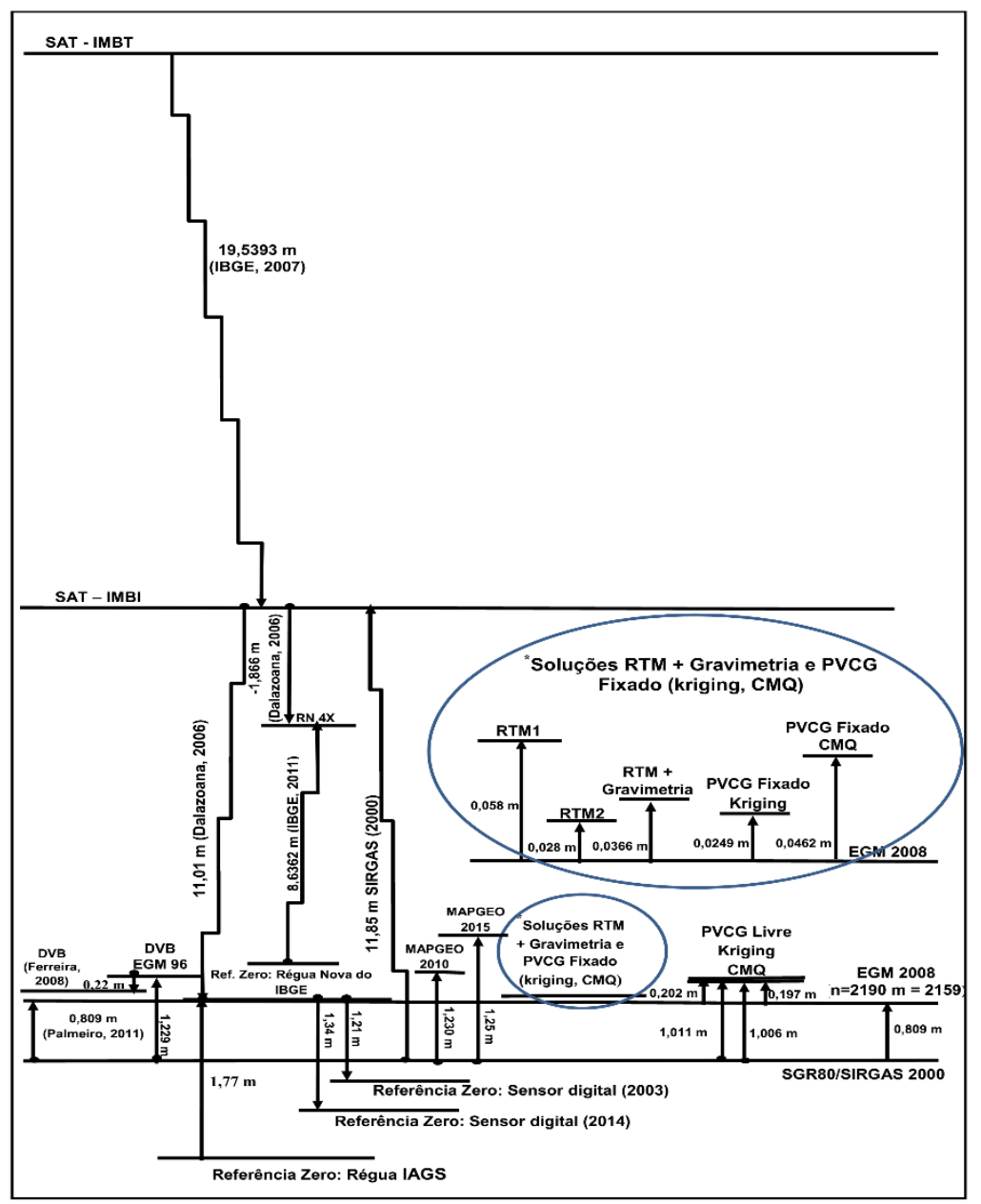

Figura 1. Relações dos zeros de referência com os níveis de referência em caráter local e global.

Fonte: Da Silva (2017) apud Atualizado e adaptado de Dalazoana (2006) e Palmeiro (2011).

Em 2007, nas proximidades do marégrafo, foi materializada a estação IMBT do SIRGAS-CON (SAT-91854 do banco de dados do IBGE). Esta estação foi estabelecida como sucessora da estação IMBI, onde foram realizadas campanhas por posicionamento GPS. Estas duas estações foram conectadas por 17 dias de observações 
GPS, adicionalmente por métodos topográficos e de nivelamento de travessia. A partir destas estações e da conexão com o marégrafo podem-se discriminar movimentos verticais locais e do NMM em relação ao centro de massa da Terra. Para controle da posição geocêntrica e vínculo do marégrafo com a estação GPS são necessários seguir alguns procedimentos primordiais, como:

- Verificação dos marégrafos (analógico (boia) e digital);

- Rastreio GNSS contínuo na estação IMBT usada para materializar a posição geocêntrica do marégrafo;

- Nivelamento geométrico das Referências de Nível (RNs) (régua maregráfica e marégrafo) localizadas na área do porto.

Há ainda vários aspectos operacionais relacionados ao DVB-I que devem ser considerados. Dentre eles pode-se destacar a busca pela recuperação de séries temporais das observações do nível do mar assim como determinar a evolução temporal da sua posição geocêntrica e a busca de alternativas para obtenção da evolução do NMM desde a definição do Datum, discriminando inclusive possíveis mudanças de tendências (Dalazoana, 2006; Luz, 2008). Outros aspectos a serem considerados estão vinculados à instrumentação empregada, como a calibração do marégrafo, por exemplo. Esta pesquisa busca abordar os aspectos relacionados que não foram considerados anteriormente nas pesquisas, no DVB-I (Da Silva, 2017).

\section{Dados disponíveis e utilizados para análise do nível do mar no DVB-I}

\section{Marégrafos}

Até o final de 1968, a estação maregráfica de Imbituba era operada e mantida pela IAGS, os dados eram digitalizados e enviados ao Permanent Service for Mean Sea Level (PSMSL). No Banco de Dados (BD) do PSMSL é possível a obtenção de médias mensais e anuais para o período de 1948 a 1968. A partir de 1969, a operação da estação ficou sob responsabilidade das autoridades portuárias brasileiras. O BD do PSMSL disponibiliza médias mensais e anuais, referentes a algumas estações maregráficas brasileiras. Os dados trabalhados foram as médias mensais, do período de setembro de 1948 a dezembro de 1968.

No final da década de 1990, a Rede Maregráfica Permanente para Geodésia (RMPG) foi proposta buscando a transição para o Datum Vertical SIRGAS e a correlação entre o DVB-I e outras referências altimétricas existentes ao longo da costa brasileira (Luz et al., 2002). As primeiras estações da RMPG foram estabelecidas em 2001, mas a operação completa foi alcançada em 2008, quando todas as cinco estações que atualmente fazem parte da RMPG passaram a ter o conjunto dos sensores maregráficos (digitais e convencionais) e réguas de marés especiais, projetadas para operação de longo prazo sem necessidade de substituição frequente (IBGE, 2013). 
Os dados utilizados da RMPG foram diários com amostragem a cada 5 minutos. O período de dados utilizados é de novembro de 2006 a 11 de janeiro de 2016, totalizando 754022 observações a cada 5 minutos.

O Centro de estudos do Nível do Mar da Universidade do Hawai (University of Hawaii Sea Level Center (UHSLC) Research Quality), em seu BD há dados horários e médias diárias das estações maregráficas ao longo da costa brasileira e de outros países. O período de dados utilizados é de 22 de agosto de 2001 a 31 de dezembro de 2007, totalizando 48319 observações horárias. Este BD também disponibiliza médias mensais as quais já passaram por um controle de qualidade. Vale ressaltar que para se trabalhar com as três séries integradas é necessário identificar qual é a referência de leitura dos distintos sensores, marégrafo convencional, marégrafo digital e régua de maré, e assim pode-se estabelecer a diferença entre eles, possibilitando interligar as séries do nível do mar.

\section{GNSS}

Um dos papeis da Rede Brasileira de Monitoramento Contínuo dos Sistemas GNSS (RBMC) é que desde 1997, vem contribuindo para a densificação regional da rede International Terrestrial Reference Frame (ITRF) e do International GNSS Service (IGS), garantindo uma melhor precisão dos produtos do IGS. O BD da RBMC disponibiliza os dados das estações, que em sua maioria fazem parte da Rede de Referência SIRGAS-CON, cujas coordenadas finais têm precisão da ordem de $\pm 5 \mathrm{~mm}$, configurando-se como uma das redes mais precisas do mundo (IBGE, 2018). As estações da RBMC desempenham o papel de Rede Geodésica de Referência para o país, no referencial SIRGAS2000. Estas estações possuem receptores com desempenho acurado, proporcionando observações e resultados de qualidade e confiabilidade.

Para investigação acerca do movimento da crosta no DVB-I, nesta pesquisa trabalhou-se com os dados disponíveis no site do IBGE, a partir do Departamento de Geodésia, mais precisamente na página da RBMC. Os arquivos das estações que fazem parte do IGS05, IGS08 e IGb08 foram obtidos via ftp - aiub/BSWUSER52. Os dados disponibilizados das estações da RBMC são diários em formato RINEX (Receiver Independent Exchange Format), correspondentes às sessões iniciadas às $00 \mathrm{~h} 01 \mathrm{~min}$ e encerradas às $24 \mathrm{~h} 00 \mathrm{~min}$, com intervalo de rastreio de 15 segundos. Os receptores das estações possuem a capacidade de rastrear satélites GPS e GLONASS. Estes coletam e armazenam continuamente as observações de código e da fase das ondas portadoras transmitidas pelos satélites das constelações.

O período de dados utilizados é de 5 de setembro de 2007 a 2 de janeiro de 2016, tendo início na semana GPS 1443 e finalizando na semana GPS 1877, totalizando 435 semanas GPS e 3042 observações para cada estação. A escolha da data para início do processamento de dados coincide com a época de materialização da estação 
IMBT. Para o processamento trabalhou-se com 35 estações distribuídas ao longo do território brasileiro.

\section{Altimetria por Satélites}

A necessidade do monitoramento do nível do mar, visando detectar sua variabilidade temporal e espacial, vem sendo estudada para análise dos efeitos climáticos e implicações em áreas costeiras. No âmbito da Geodésia, utilizam-se dados provenientes do monitoramento do nível do mar em um sentido muito mais amplo do que a realização da referência para as redes verticais clássicas. Tal é o caso do estudo dos efeitos de variação do NM na rotação da Terra realizado pelo International VLBI Service for Geodesy and Astrometry (IVS) (IERS, 2018).

A altimetria por satélites fornece uma série temporal de dados mais curta (cerca de 26 anos até o presente) quando comparada com a série temporal de dados provenientes de marégrafos (existem séries de mais de 150 anos de observações). Mesmo assim, a altimetria por satélite é uma técnica promissora para a detecção de variações no NMM porque o faz de forma independente de movimentos crustais e com grande cobertura espacial.

Foram utilizados os dados disponíveis no site do DGFI (Deutsches Geodätisches Forschungsinstitut), mais precisamente do Open Altimeter Database (OpenADB). Destaca-se que os dados fornecidos para as diferentes missões já possuem certo grau de processamento, mas que dependendo do objetivo da pesquisa é necessário realizar alguns ajustes ou correções. Como se busca solucionar a questão de dados descontínuos do marégrafo trabalhou-se com distintas missões altimétricas.

Os dados das missões altimétricas disponibilizados no BD do DGFI estão em formato binário (NETCDF). Seguem uma estrutura sequencial, usualmente hierárquica, onde a missão corresponde $n$ ciclos e $m$ passes. Geralmente a partir dos ciclos se identificam o período de repetição, onde os passes das trilhas (em inglês ground track) significam a projeção da órbita do satélite na superfície da Terra, e o satélite realiza as observações. Estas em função de sua passagem em determinada região são ascendentes e descendentes. A intersecção entre um passe ascendente e descendente refere-se aos pontos de crossover.

Destaca-se que para se obter tanto a cobertura espacial quanto a resolução temporal é necessário realizar uma combinação de dados obtidos a partir de diferentes missões com diferentes padrões de recobrimento. Os dados de todas as missões altimétricas disponibilizados no BD do DGFI já foram anteriormente calibrados e corrigidos, assim como combinados. Sendo assim, foi possível a combinação dos produtos de todas as missões, nesta pesquisa. Vale ressaltar que a combinação de dados de diferentes missões espaciais requer a padronização dos dados bem como dos sistemas de referência. Salienta-se que os elipsoides utilizados pelas distintas missões da altimetria por satélite também são diferentes, como pode ser visto na Tabela 1. Neste 
estudo foram utilizados dados derivados de oito missões altimétricas em sua configuração orbital original, os dados englobam um período de aproximadamente vinte e cinco anos (julho de 1991 a setembro de 2015), como apresentado na Figura 2.

\section{Tabela 1}

Parâmetros relevantes do elipsoide de referência para transformação para um único SGR

\begin{tabular}{lcccc}
\hline \multicolumn{1}{c}{ Parâmetros } & $\begin{array}{c}\text { T/P, JASON-1 } \\
\text { e 2, e GFO }\end{array}$ & $\begin{array}{c}\text { ERS-1 e 2, } \\
\text { ENVISAT } \\
\text { SARAL }\end{array}$ & WGS-84 & GRS-80 \\
\hline $\begin{array}{l}\text { Semieixo maior } \\
\text { (a) - m }\end{array}$ & 6378136,300000 & 6378137,000000 & 6378137,000000 & 6378137,000000 \\
$\begin{array}{l}\text { Semieixo menor } \\
\text { (b) - m }\end{array}$ & 6356751,600563 & 6356752,314245 & 6356752,314245 & 6356752,314140 \\
$\begin{array}{l}\text { Achatamento } \\
\text { (1/f) }\end{array}$ & $1: 298,257$ & $1: 298,257223563$ & $1: 298,257223563$ & $1: 298,257222101$ \\
$\begin{array}{l}\text { Excentricidade } \\
\text { (e) }\end{array}$ & 0,081819221456 & 0,081819190843 & 0,081819190843 & 0,0818191910435 \\
\hline
\end{tabular}

Observa-se na Figura 2 que a missão T/P apresenta o maior período de dados, mas, como se tem a série temporal GNSS do período de 2007 a 2015, escolheu-se a missão JASON-2 para ser utilizada na comparação com a série maregráfica. Esta missão foi escolhida para validar a metodologia que foi então empregada em todas as outras missões apresentadas na Figura 2. Destaca-se que a missão JASON-2 teve duração do ano de 2008 a 2015 e a série da RMPG tem observações de 2006 a 2016 , sendo assim foram utilizados aproximadamente sete anos para comparação.

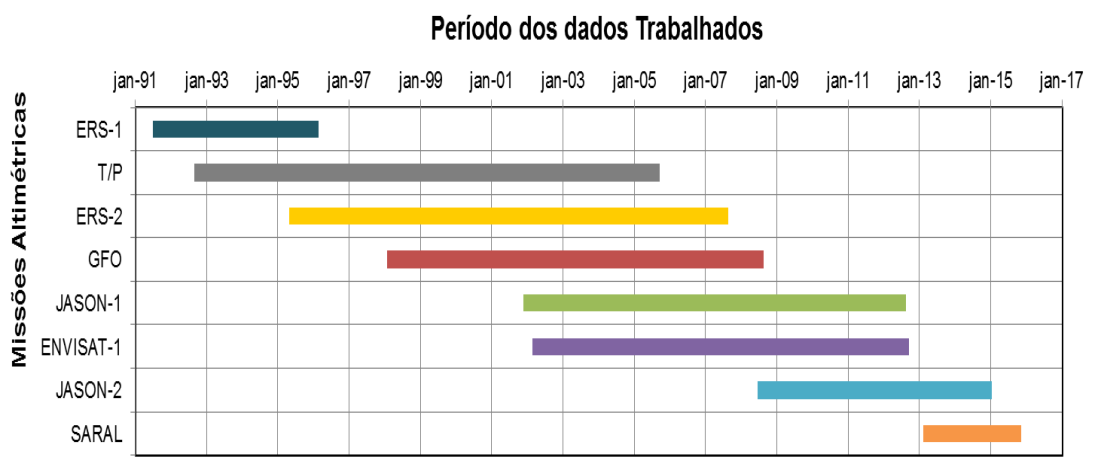

Figura 2. Período de disponibilidade de dados advindos da altimetria por satélite utilizados nesta pesquisa. 


\section{Aspectos metodológicos para análise da evolução temporal do DVB-I}

A integração da técnica de altimetria por satélites e dados de marégrafos pode ser empregada no monitoramento das variações e da evolução do NMM desde que acompanhados do monitoramento de deslocamentos da crosta. Tal é a possibilidade advinda da utilização de séries temporais de dados de marégrafos associados com o GNSS. Assim, é possibilitada a detecção de movimentos da crosta necessários para obtenção de variações absolutas do NMM. Estes são certamente pressupostos para a modelagem do DVB-I de forma a evitar-se que movimentos verticais da crosta sejam interpretados como variações do NMM, como é representado na Figura 3. Outro ponto a destacar é que na falta de uma estação GNSS pode-se utilizar um gravímetro.

Destaca-se que a determinação das coordenadas geocêntricas a partir do processamento GNSS, o cálculo das velocidades de uma estação e as séries temporais provenientes de observações maregráficas, permitem definir o NMM em um SGR geocêntrico, obtendo valores do nível do mar em relação ao centro de massa da Terra e não relativos à estrutura na qual o marégrafo encontra-se fixo. Isto possibilita a comparação do NMM com os dados provenientes da altimetria por satélites. Possibilitando relacionar as séries temporais de nível do mar obtidas com o marégrafo com as séries de dados provenientes do emprego de modelos da altimetria por satélites.

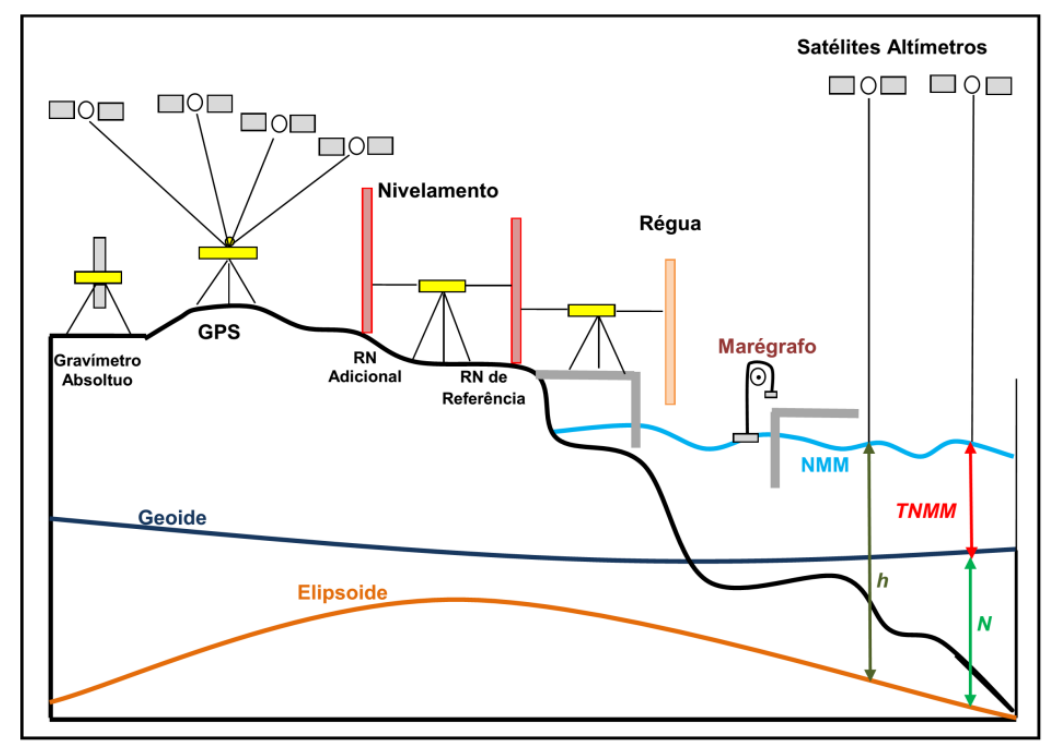

Figura 3. Apresenta um esquema importante para se vincular sensores distintos. Como por exemplo, as estações GNSS da RBMC têm instalações distintas dos sensores maregráficos. Então, para que se possa integrar os dados provenientes de distintos sensores é necessário vincular os sensores do marégrafo e da régua com o pilar GNSS via nivelamento geométrico. 
Vários estudos vêm sendo desenvolvidos utilizando os aspectos apresentados na Figura 4. Dalazoana e De Freitas (2006) mostraram os resultados baseados em dados maregráficos e de nivelamento, evidenciavam uma elevação no NMM no Porto de Imbituba em torno de $2 \mathrm{~mm} /$ ano. Estes resultados foram obtidos com integração, com base em altimetria por satélites, das séries temporais armazenadas no banco de dados do PSMSL e dados digitais de 2001 a 2004. Da Silva e De Freitas (2014), a partir de séries temporais de processamento GNSS, associadas com as séries maregráficas de 2007 a 2014, obtiveram uma elevação no NMM no Porto de Imbituba em torno de 2,4 mm/ano. Da Silva e De Freitas (2015), a partir da integração de dados de altimetria por satélites, das séries temporais armazenadas no banco de dados do PSMSL e dados maregráficos de 2006 a 2015, obtiveram uma elevação no NMM em torno de 2,05 mm/ano. Da Silva et al. (2016) obtiveram a mesma elevação que Da Silva e De Freitas (2014).

\section{Análises metodológicas e dos resultados acerca da evolução temporal do DVB-I}

\section{Marégrafos}

Em algumas situações observou-se que as séries temporais possuem leituras possivelmente anômalas ou com ausência de dados. Estes aspectos geralmente ocorrem por mudanças de equipamentos ou reposicionamento de sensores, anomalias reais no NM ou até mesmo devido o equipamento passar alguns dias até meses inativo. A Figura 4 mostra um exemplo de inatividade diária (dia 12), a série horária apresentada é do marégrafo digital de Imbituba para o mês de março de 2013.

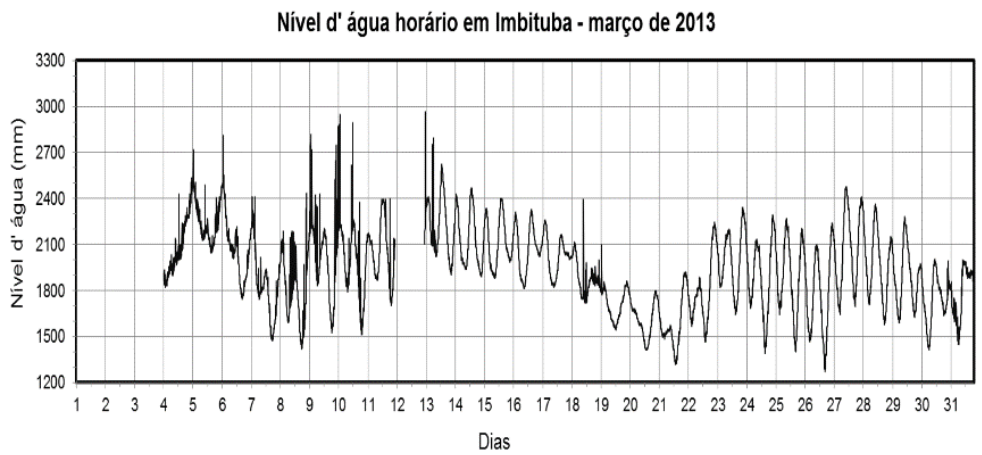

Figura 4. Série temporal de observações do nível d'água - Março de 2013, do marégrafo de Imbituba para análise de anomalias nas observações.

Como já mencionado, trabalhou-se com os dados disponíveis nos sites do IBGE, UHSLC e do PSMSL. Os dados disponibilizados pelo IBGE para Imbituba são diários com amostragem a cada 5 minutos. Então foi necessário desenvolver scripts para 
leituras e concatenação dos dados. Primeiramente desenvolveu-se um script em Python para leitura dos dados. Após este processo é efetivada uma verificação de consistência e sua importação para o banco de dados desenvolvido no MySQL.

Os dados obtidos do marégrafo de Imbituba disponibilizados pelo IAGS no BD do PSMSL, no BD da UHSLC e no BD do IBGE - RMPG são séries de observações obtidas por distintos equipamentos. Isto implica que há diferenças nas referências das leituras. Para compatibilização das séries (IAGS e RMPG) estimou-se as diferenças ou o "zero" entre a referência das mesmas a qual cada série está vinculada. Para a integração dos dados da RMPG e da UHSLC com os do PSMSL foram utilizados os dados do Teste Van de Casteele realizado em junho de 2003 e em maio de 2014. Adicionalmente utilizou-se o trabalho realizado por Dalazoana (2006). Estes foram utilizados para estimar as diferenças na referência zero do sensor digital, régua maregráfica e do sensor analógico existentes em Imbituba. Têm-se como referências geométricas primárias os sensores nas estações GNSS (IMBI SAT - 91854) e a atual estação SIRGAS-CON (IMBT SAT - 94024). Para estimar a diferença entre a referência do sensor digital e a referência dos dados do IAGS, utilizou-se o trabalho realizado por Dalazoana (2006) e as informações apresentadas na Figura 1. Ao analisar a série temporal obtida da RMPG e a série temporal obtida da UHSLC, evidenciouse que as séries apresentam mesmo comportamento. Sendo assim, para integração considerou-se que o sensor digital referido aos dados da UHSLC refere-se ao sensor do IBGE de 2002 e 2003.

Foi realizada a análise estatística de regressão das observações mensais do nível do mar do marégrafo de Imbituba, evidenciando o coeficiente de correlação muito forte $(0,99)$. Vale ressaltar que para a obtenção da estatística de regressão, considerou-se o nível de confiança de $95 \%$. Em vista das correlações evidenciadas estima-se que se pode trabalhar com os dados mensais para se determinar as elevações do NM em $\mathrm{mm} / \mathrm{ano}$.

Após as análises, filtragem e compatibilização das séries, realizou-se a integração das séries UHSLC+RMPG (indicou uma elevação de cerca de $6,90 \mathrm{~mm} /$ ano, período de 2001 a 2016). Resultados do último relatório do IBGE (2016) apresentam resultados similares para este mesmo período analisado, uma variação do NMM relativo de $6,60 \mathrm{~mm} / \mathrm{ano}$. A integração das três séries (IAGS + UHSLC + RMPG) indicou uma elevação de cerca de 3,10 mm/ano, Figura 5, período de 1948 a 1968 e de 2001 a 2016.

Na Figura 5 percebe-se uma lacuna de dados do período de 1968 a julho de 2001. Isto se deve ao fato que o IAGS só obteve dados das autoridades brasileiras, até 1968. Assim como, a implantação do marégrafo de Imbituba ter sido realizada depois. 


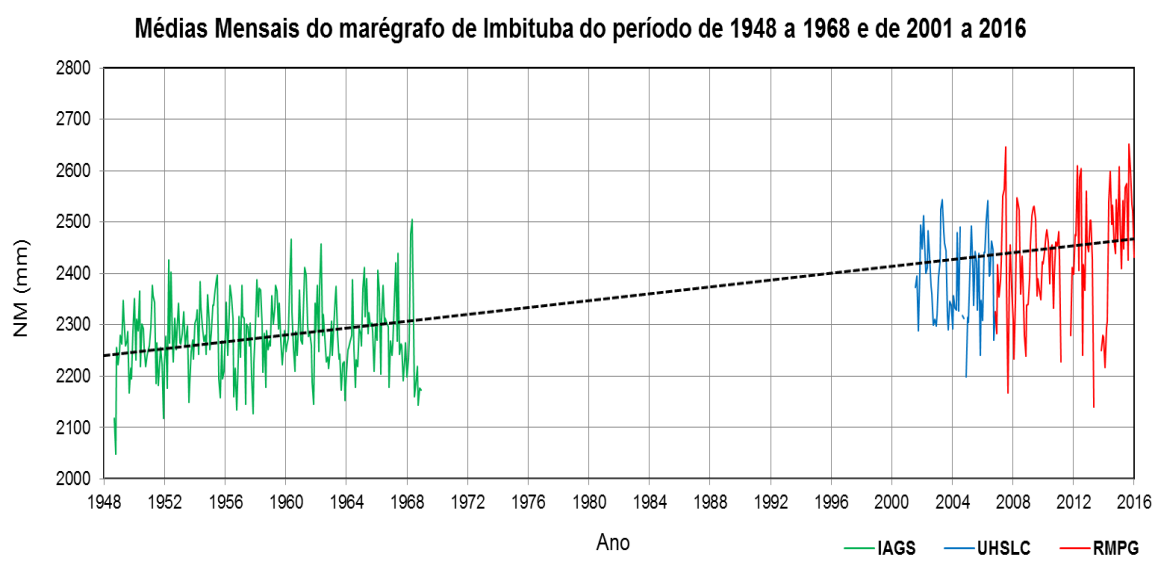

Figura 5. Integração das séries temporais (IAGS + UHSLC + RMPG) do nível do mar em Imbituba.

\section{GNSS}

Para se trabalhar com o conjunto de dados GNSS, verificou-se a consistência dos dados. A média anual da disponibilidade dos dados é acima de 90\%. Destaca-se que algumas estações apresentaram mais disponibilidade nos dados comparados a outras estações, por exemplo, a estação UFPR apresenta uma média de 99,78\% na disponibilidade dos dados; em contrapartida a estação que apresenta menor disponibilidade é a de CRUZ com uma média de 62,39\%, como se apresenta na Figura 6. Vale ressaltar que a estação IMBT é o objeto de estudo. Esta apresenta uma disponibilidade de dados de $84,77 \%$ ao longo do período analisado.

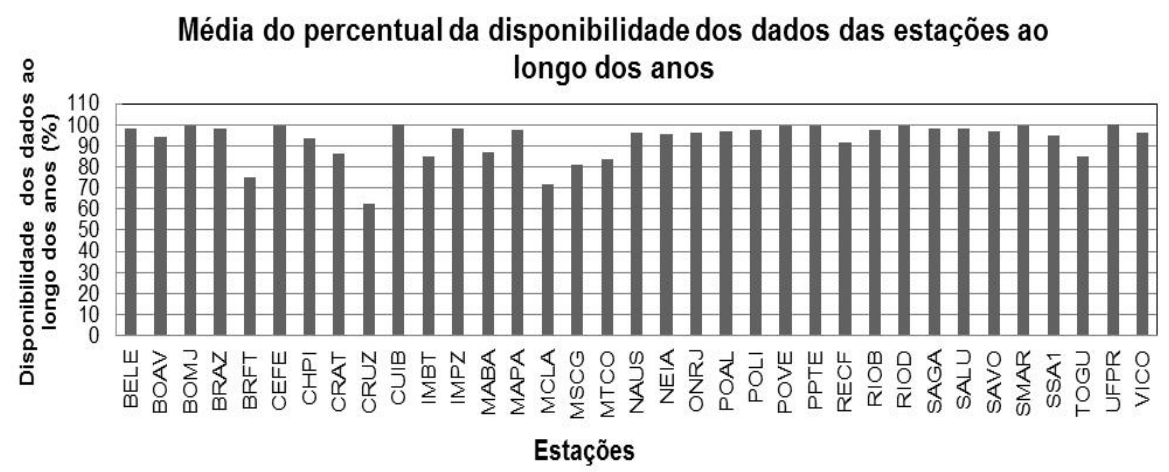

Figura 6. Média do percentual de disponibilidade dos dados das estações ao longo do período de setembro de 2007 a janeiro de 2016 
Trabalhou-se com 98748 arquivos RINEX dos dados das estações GNSS obtidas da RBMC, correspondendo a um total de aproximadamente 420 Gigabytes de dados brutos. Após a seleção dos dados, foram definidas as principais informações e estratégias que seriam utilizadas no processamento dos dados GNSS no Bernese 5.2, como se apresenta na Tabela 2. Estas informações precisam estar bem definidas, pois o software Bernese é formado por um conjunto de programas que desempenham funções distintas dentro de um processamento de dados GNSS, para mais detalhes ver Da Silva (2017).

A partir do modo BPE (Bernese Processing Engine) realizou-se o processamento automatizado no software Bernese 5.2. Para o feito, desenvolveram-se dois scripts (extensão PCF) um diário baseado no RNX2SNX (RINEX para SINEX) do Bernese 5.2 (Dach, 2011) e um semanal baseado no SEMAN1584 do IBGE (IBGE, 2011), como pode ser visto em Da Silva (2017). O script semanal é utilizado ao finalizar o processamento diário, pois sua utilização é para avaliar as séries e realizar a combinação das soluções diárias em uma única solução.

Vale ressaltar que no processamento semanal a coordenada de cada estação é reduzida ao dia médio de cada semana GPS processada. Para geração das séries temporais é importante o conhecimento dos dados de entrada, as análises dos dados de saída e a validação dos resultados. No processamento diário são gerados dois arquivos importantes a serem utilizados no processamento semanal, um contém as coordenadas finais e outro contém as equações normais. A combinação das soluções diárias é realizada a partir de um ajustamento por mínimos quadrados das equações normais, onde se estima as coordenadas e velocidades a priori das estações. Na combinação de soluções GNSS podem-se realizar dois tipos de soluções: rede injuncionada (ponderação das coordenadas e velocidades a priori das estações de referência) e rede livre. Nesta pesquisa aplicaram-se as duas configurações.

Quando se trabalha com rede injuncionada podem-se aplicar três estratégias distintas: minimum constraint, coordenadas de referência injuncionadas e coordenadas fixadas. Sendo assim, utilizou-se a solução com a condição de minimum constraint, onde as coordenadas de referência foram injuncionadas fracamente para que as inconsistências apresentadas por Gregorius (1996) não ocorressem. Destaca-se que as vantagens de utilizar minimum constraint são as de: sua solução é obtida a partir de três translações, os erros nas coordenadas de referência são pequenos e não distorce a geometria da rede. Segundo Dach et al. (2015) essa condição é a mais recomendada para se obter as soluções finais. 
Tabela 2

Principais Informações utilizadas no processamento dos dados GNSS para deteç̧ão do movimento da crosta

\begin{tabular}{|c|c|}
\hline Período & Semana GPS: 1443 a $1877^{(*)}$ \\
\hline Observações & GNSS: Código e Fase (dupla diferença) \\
\hline Software & Bernese 5.2 (modo BPE) \\
\hline Número de Estações & 35 estações (Extensão YYO $\left.{ }^{1}\right)$ \\
\hline Taxa de Coleta & 30 segundos \\
\hline Ângulo de Elevação & $3^{\circ}$ \\
\hline Estratégia de Linha de Base & OBS-MAX \\
\hline Órbita & $\begin{array}{l}\text { Produtos do centro de análise CODE contendo as análises } \\
\text { das órbitas GNSS (GPS e GLONASS) - Final IGS05, } \\
\text { IGS08 e IGb08 } 08^{(*)}\end{array}$ \\
\hline Modelo de Nutação & IAU2000R06 \\
\hline Modelo de Polo & IERS2010XY \\
\hline Efemérides Planetárias & DE405.PH \\
\hline Modelo Global de Gravidade & EGM2008 \\
\hline Marés Oceânicas & OT_FES2004.TID \\
\hline Maré da Terra Sólida & TIDE2000 \\
\hline $\begin{array}{l}\text { Redução da carga dos efeitos } \\
\text { troposféricos a priori }\end{array}$ & Dry_GMF² (Na etapa de detecção dos resíduos - GPSEST) \\
\hline $\begin{array}{l}\text { Estimativa dos parâmetros do atraso } \\
\text { troposféricos: Zênite e Gradiente }\end{array}$ & $\begin{array}{l}\text { Wet_GMF}{ }^{2} \text { (Etapa de detecção dos resíduos: Zênite }-2 \text { ho- } \\
\text { ras; Sigma a priori relativo }-5 \mathrm{~m} \text { Gradiente }-24 \text { horas; } \\
\text { Sigma a priori relativo }-5 \mathrm{~m} \text { ) }\end{array}$ \\
\hline Estimativa da Troposfera & Modelo Troposférico VMF³ (Solução Final) \\
\hline Ambiguidades & $\begin{array}{l}\text { Estratégia baseada em observações, distância e tempo. } \\
\text { QIF }^{4} \text { - linhas de base maiores que } 2000 \mathrm{~km}\end{array}$ \\
\hline $\begin{array}{l}\text { Unificação da referência das } \\
\text { diferentes técnicas do rastreamento } \\
\text { dos receptores }\end{array}$ & Correções DCB ${ }^{5}$ \\
\hline Modelo de Ionosfera & $\begin{array}{l}\text { Global Ionosphere Maps (diário, com extensão ION) obtido } \\
\text { do CODE }\end{array}$ \\
\hline Modelo de Carga Oceânica & FES2004 (extensão BLQ) \\
\hline Redução de Carga Atmosférica & Carga atmosférica (extensão ATL) \\
\hline Definição da Placa Oceânica & South American - SOAM (extensão PLD) \\
\hline Dados Meteorológicos & Imbituba e Florianópolis (extensão MET) \\
\hline Variação de Centro de Fase & Absoluto (IGS05, IGS08 e IGb08) \\
\hline Coordenadas e Velocidades & (IGS05, IGS08 e IGb08) \\
\hline Soluções Diárias & $\begin{array}{l}\text { Soluções Semilivres - Todas as estações injuncionadas em } \\
\sigma= \pm 1 \mathrm{~m} \text {. Arquivos de saída: } \text { SINEX }^{6}\end{array}$ \\
\hline Tempo de Processamento & Cerca de 9 horas \\
\hline Soluções Semanais & $\begin{array}{l}\text { Soluções Semilivres - Injuncionadas em } \sigma= \pm 1 \mathrm{~m} \text {. } \\
\text { Arquivos de saída: SINEX }\end{array}$ \\
\hline Tempo de Processamento & Cerca de 30 minutos \\
\hline
\end{tabular}

(*) Semanas GPS: 1443 a 1631 - IGS05; 1632 a 1708 - IGS08; 1709 a 1877 - IGb08

${ }^{1}$ Indica os dois últimos dígitos do ano da observação $/{ }^{2}$ Global Mapping Function $/{ }^{3}$ Vienna Mapping Function $/{ }^{4}$ Quasi-Ionosphere Free $/{ }^{5}$ Differential (P1-C1) Code Biases $/{ }^{6}$ Software Independent Exchange

Vale ressaltar que diante dos subitens apresentados, as informações foram organizadas de forma que se consiga identificar os aspectos referentes ao movimento da crosta. Como a estação IMBT é o objeto de estudo desta pesquisa, então a velocidade da componente $u p$, obtida a partir do processamento GNSS foi comparada com os 
resultados das velocidades a partir do Modelo VEMOS2015 sugerido pelo SIRGAS. Como resultado do processamento das semanas GPS 1443 a 1877, software Bernese 5.2 , observa-se que há uma subsidência na estação IMBT (componente $U P$ ), uma taxa de $-3,02 \mathrm{~mm} /$ ano, Figura 7 . Em contrapartida com a utilização do modelo de velocidade VEMOS2015, obteve-se -3,40 mm/ano. Destaca-se que o valor obtido no processamento, representa de forma mais realística o movimento da estação IMBT.

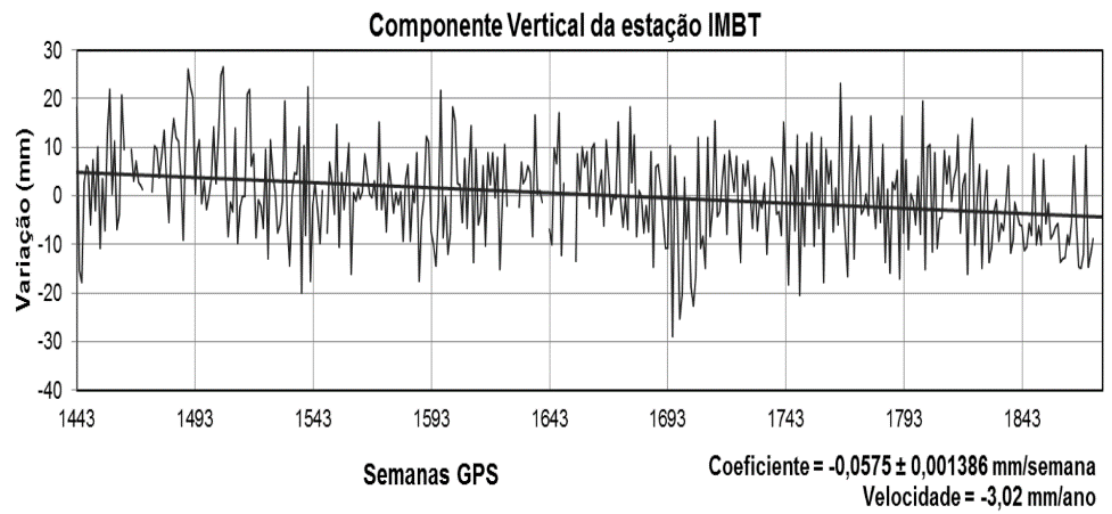

Figura 7. Variação Temporal, coeficiente de variação e velocidade da componente vertical da estação IMBT.

A estimativa da tendência determinada para a estação IMBT pode ser utilizada para determinação da posição geocêntrica do marégrafo do DVB-I, pois apresenta uma série temporal com mais de 5 anos de processamento de dados e a série temporal gerada está em consonância com a elaborada pelo IBGE e SIRGAS.

\section{Integração das séries temporais: dados maregráficos, observações GNSS e dados provenientes da Altimetria por Satélites}

Os dados no BD do DGFI encontram-se armazenados em formato binário. Para se realizar a leitura destes arquivos e para análise das informações específicas foram desenvolvidas nesta pesquisa rotinas em linguagem Python. Também foi necessário desenvolver rotinas para análise das informações maregráficas, devido à necessidade de se ter as informações no mesmo instante de tempo dos dados provenientes da altimetria por satélites.

Os dados da $\mathrm{SSH}$ utilizados para análise foram considerados dentro do intervalo de $S S H_{M} \pm 3 \sigma$. Destaca-se que $S S H_{M}$ é o valor médio da $S S H$ para o período analisado e $\sigma$ o desvio padrão da média. Evidencia-se que a série temporal das observações maregráficas é horária e o efeito do barômetro inverso não foi corrigido. Como é 
necessário que as séries temporais sejam compatíveis, foi preciso eliminar as correções das marés oceânicas e barômetro inverso que estavam aplicadas aos valores de $\mathrm{SSH}$. Isto foi realizado para que se possa assumir que tanto os marégrafos como os satélites altímetros estão observando o mesmo sinal oceanográfico.

Para reamostragem da série maregráfica do NM em Imbituba obtida da RMPG (horária) no mesmo instante de tempo das séries de $S S H$ da altimetria por satélites, realizou-se interpolação cúbica. Os detalhes do desenvolvimento da interpolação cúbica podem ser vistos em Alves et al. (2005). Destaca-se que esse processo também foi realizado para as séries temporais maregráficas horárias do $\mathrm{NM}$ obtidas da UHSLC. Os valores de $S S H$ vêm com dia Juliano, então as séries maregráficas foram colocadas na mesma referência temporal. Neste trabalho o dia Juliano 0 foi estabelecido como às 12:00 horas TU de 1/1/2000.

$\mathrm{Na}$ comparação entre observações maregráficas e dados provenientes de missões altimétricas, duas situações são consideradas possíveis e importantes a serem levadas em conta: as observações maregráficas precisam ter a mesma amostragem dos dados dos satélites altímetros; e é preciso trabalhar com uma série temporal de observações maregráficas com no mínimo 5 anos.

Nesta pesquisa para comparação das séries de observações maregráficas com as séries de $S S H$ foi preciso considerar a trilha do satélite mais próxima do marégrafo. A comparação foi feita considerando as 71 células mais próximas do marégrafo. Destaca-se que o conjunto de células compreende dados localizados até aproximadamente a $500 \mathrm{~km}$ da costa. Sendo assim o mais importante é considerar a célula mais próxima da costa onde o desvio padrão das observações ainda se situa dentro de valores aceitáveis por não terem sido afetados por efeitos costeiros. O comprimento da célula está relacionado com a amostragem dos dados que é fornecida para os usuários, a taxa de amostragem fornecida é de $1 \mathrm{~Hz}$ ( 1 observação por segundo), considerando a velocidade do satélite isso resulta em 1 observação a cada $\pm 7 \mathrm{~km}$ de comprimento contadas a partir da linha do equador.

Para todas as missões altimétricas foram feitas comparações utilizando como base o coeficiente de correlação e o desvio padrão entre as séries temporais do marégrafo e na célula. Observou-se nas análises, da missão JASON-2 utilizada para validação da metodologia, que a célula mais próxima da costa (cerca de $56 \mathrm{~km}$ ) era a de número 475 , com coeficiente de correlação de 0,78 e desvio padrão de $76 \mathrm{~mm}$. Porém, os melhores resultados foram obtidos para a célula 478 (cerca de $77 \mathrm{~km}$ ), com coeficiente de correlação de 0,93 e desvio padrão de $69 \mathrm{~mm}$. Após as análises das células das missões, realizou-se a comparação relativa entre a série temporal maregráfica e a série temporal da missão altimétrica JASON-2, uma vez que as duas séries não possuem zeros de referências iguais. Para melhorar a comparação das séries no intuito de integrar, aplicou-se uma correção diferencial de maré baseada nas componentes harmônicas, mais detalhes em Da Silva (2017). Após a correção de maré foi realizada 
a análise do coeficiente de correlação e do desvio padrão, obtendo os seguintes valores para a célula 478: 0,96 e 50mm, respectivamente. Estas análises foram realizadas para todas as missões, mais detalhes em Da Silva (2017).

Como as células estão distantes da costa, foi necessário realizar a extrapolação dos dados. Sendo assim, foi considerado o estudo realizado por Dalazoana (2006) para os marégrafos de Ilha Fiscal e Cananeia. A partir de um polinômio de segundo grau, estimou-se o valor de $S S H$ na célula que correspondia à posição do marégrafo de Imbituba $\left(S S H_{C E L M I}\right.$ e em cada ciclo era considerado o perfil da $S S H$ nas 71 células mais próximas do marégrafo. O polinômio pode ser escrito, segundo Dalazoana (2006), como a equação (1):

$$
S S H_{C E L M I}=\alpha+b(C E L M I)+c(C E L M I)^{2}
$$

Na equação (1) os coeficientes (a, b e c) são calculados em função dos valores da $S S H$ nas 71 células evidenciadas mais próximas do marégrafo; CELMIé a célula que indicaria à posição do marégrafo, sendo estimada a partir da distância entre o marégrafo e a célula dos dados de $S S H$ mais próxima, assim como se leva em consideração o comprimento de $7 \mathrm{~km}$ da célula.

Para gerar a série temporal dos valores de $S S H$ extrapolados a partir das missões altimétricas, calculou-se para cada ciclo das missões um valor de SSH. Para realizar a comparação da série temporal das observações maregráficas com a série gerada para os valores de $S S H_{C E L M I}$, aplicou-se interpolação cúbica, nas observações derivadas do marégrafo para o mesmo instante da série temporal do SSHCELMI.

Como após a correção diferencial de maré, os dados são mais compatíveis, sendo assim, a extrapolação foi realizada para os dados dos altímetros com correção. Vale destacar que se realizou a compatibilização do referencial das missões altimétricas, onde se aplicou a metodologia desenvolvida por Keysers et al. (2013, p.110).

Geralmente o NMM tem um comportamento local distinto quando comparado aos resultados globais, isto decorre do fato de existirem regiões nas quais a tendência é de elevação do NMM e há regiões com tendência de descensão do NMM. Pode-se supor que a taxa de variação temporal do NMM observada pelo satélite altímetro é a mesma que a variação temporal observada pelo marégrafo com a consideração dos possíveis movimentos da crosta determinada pelo processamento GNSS. Onde se pode escrever na forma da equação (2):

$$
\text { Tendência Marégrafo }+ \text { Tendência } G N S S-\text { Tendência } a_{\text {Altimetria }}=0
$$

Vale destacar que o posicionamento GNSS é muito importante na discriminação dos possíveis movimentos da crosta. Trabalhou-se com um período de aproximadamente 25 anos de dados altimétricos. Deste período, 9 anos de dados altimétricos 
foram utilizados para preencher a inexistência de dados na série temporal das observações maregráficas. E 8 anos foram utilizados para substituir as médias das observações maregráficas consideradas como outliers. Destaca-se que foram utilizados 17 anos de missões altimétricas para preencher as lacunas existentes entre os dados maregráficos e as observações maregráficas detectadas como outliers, disponibilizados pela UHSLC e pela RMPG, devido às intempéries existentes ao longo do tempo.

As estimativas de tendência dependem da amostragem e do período trabalhado. Adicionalmente devem-se levar em conta as correções aplicadas aos dados, assim como se discriminar possíveis movimentos da crosta e realizar a correção desses efeitos nas observações maregráficas. Com a utilização de observações maregráfica obtidas dos BD do PSMSL, UHSLC e RMPG dos períodos de setembro de 1948 a dezembro de 1968, agosto de 2001 a setembro de 2007, novembro de 2006 a janeiro de 2016, respectivamente, destaca-se que os dados maregráficos apresentam descontinuidades, as quais foram preenchidas com os dados de altimetria por satélite do período de setembro de 1992 a setembro de 2015. O processamento dos dados GNSS para obtenção da componente altimétrica, do período de setembro de 2007 a janeiro de 2016, auxiliou na determinação da tendência da variação temporal do NMM em Imbituba. A Figura 8 apresenta a integração das séries das observações maregráficas com os dados das missões altimétricas. Para isto, foi desenvolvido um script em Python para que se pudesse concatenar as médias que estavam em dias julianos para médias mensais.

Destaca-se que a tendência do marégrafo de Imbituba foi considerada do período de 2007 a 2016, obtida com os dados da RMPG, onde apresentou uma tendência de $5,26 \mathrm{~mm} / \mathrm{ano} \pm 0,11 \mathrm{~mm} / \mathrm{ano}$. A tendência da coordenada altimétrica foi obtida a partir do processamento dos dados no software Bernese 5.2, onde apresentou uma tendência de $-3,02 \mathrm{~mm} / \mathrm{ano} \pm 0,39 \mathrm{~mm} / \mathrm{ano}$. E a tendência do altímetro foi obtida a partir das missões altimétricas com a correção oceânica, sendo uma tendência de $2,23 \mathrm{~mm} /$ ano $\pm 0,42 \mathrm{~mm} / \mathrm{ano}$. Vale destacar que se considerou este período, devido coincidir com a materialização da estação GNSS IMBT.

Aplicando estas tendências na equação (2) evidenciou-se que existe uma evolução do NMM na região do DVB-I pela determinação da variação temporal resultante de aproximadamente $+2,24 \mathrm{~mm} /$ ano. Esta variação está em concordância com as medições realizadas pelo NOAA (2016), onde se destaca uma variação de aproximadamente $2,9 \mathrm{~mm} /$ ano $\pm 0,4 \mathrm{~mm} /$ ano, no período de 09/1992 a 03/2016 e o AVISO (2016) que obteve uma variação global de aproximadamente $3,36 \mathrm{~mm} / \mathrm{ano} \pm 0,1$ mm/ano, no período de 1993,01 a 2015,97. 
Estimativa do Nível Médio do Mar em Imbituba com dados altimétricos e maregráficos após correção do movimento da crosta

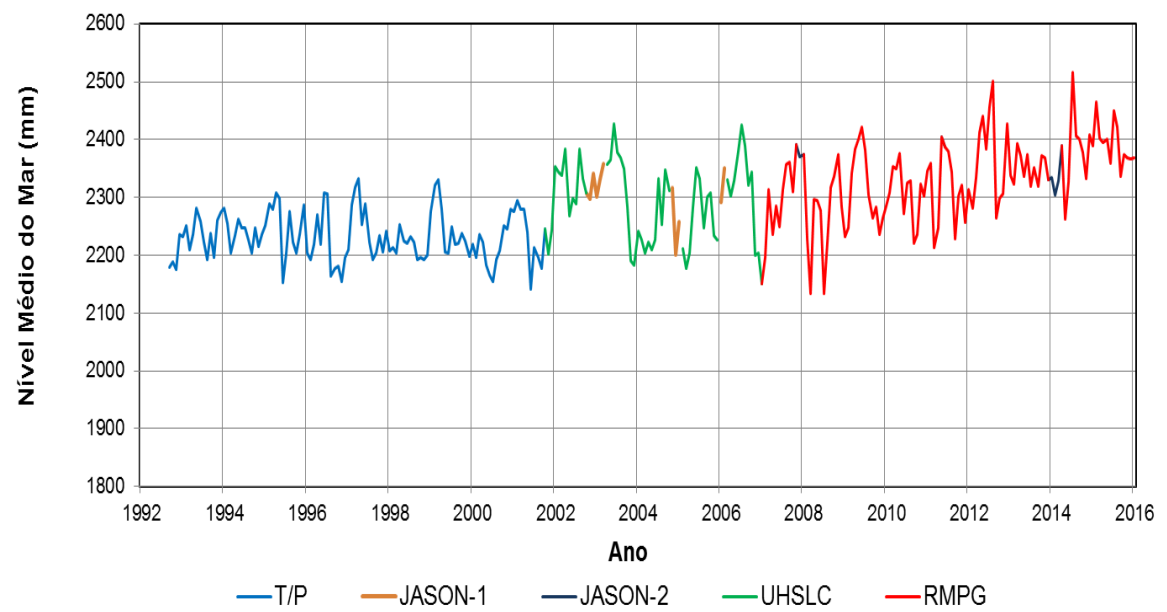

Figura 8. Estimativa do nível médio do mar em Imbituba do período de 1992 a 2016, com os dados das missões altimétricas e observações maregráficas após a correção do movimento da crosta.

\section{Conclusão}

Os estudos da análise da evolução temporal do Datum Vertical Brasileiro de Imbituba se deram com a utilização de dados provenientes de séries temporais do posicionamento GNSS, de observações maregráficas e de dados provenientes da altimetria por satélites, tendo como objetivo proposto analisar a evolução temporal do DVB-I, para detectar possíveis movimentos da crosta e a evolução do nível médio do mar local.

As observações GNSS também foram utilizadas para o controle da posição geocêntrica do marégrafo. Os dados foram processados com o software Bernese 5.2. Junto à estação IMBT foram processadas mais 34 estações, todas de monitoramento contínuo, com o objetivo de aumentar a estabilidade da solução semanal. A componente altimétrica foi estimada diariamente, mas realizou-se o processamento semanal onde se considera o dia médio da semana. Cada semana apresentou um valor diferente, no final do processamento estimou-se o coeficiente semanal que foi de $-0,0633$ $\mathrm{mm} / \mathrm{semana}$. E a taxa de subsidência de $-3,02 \mathrm{~mm} / \mathrm{ano}$, período de setembro de 2007 a janeiro de 2016, destaca-se que este valor é próximo ao de -3,4 mm/ano calculado utilizando o modelo VEMOS2015.

As observações provenientes do marégrafo de Imbituba (RMPG) foram filtradas visando sua integração com os dados armazenados no banco de dados do PSMSL e do UHSLC. A integração destas séries indicou uma tendência de elevação do nível do mar em uma taxa de $3,10 \mathrm{~mm} / \mathrm{ano}$, sem considerar possíveis movimentos da 
crosta, período de setembro de 1948 a dezembro de 1968 e de agosto de 2001 a janeiro de 2016. O resgate das informações do nível do mar provenientes dos dados registrados no marégrafo no DVB-I possibilitou uma melhor análise por estar se trabalhando com uma série temporal longa. Analisando as observações maregráficas da RMPG, mesmo período da análise das observações da RBMC, obteve-se uma variação temporal de $5,26 \mathrm{~mm} / \mathrm{ano}$. Sendo assim, a partir das análises da tendência temporal do NMM no DVB-I discriminando movimentos do NMM e da crosta por intermédio dos dados maregráficos integrados com séries temporais do posicionamento GNSS, obteve-se uma elevação de 2,24 mm/ano, para o período de 2007 a 2016.

Para melhor análise do nível médio do mar, analisaram-se dados oriundos de distintas missões de altimetria por satélite. Assim como, com a utilização de distintas missões altimétricas confirmou-se os problemas referentes à perda de resolução dos altímetros nas proximidades da costa. Para todas as missões analisadas evidenciouse que as células que estavam mais próximas da costa possuíam coeficientes de correlação mais baixos e desvios padrão maiores do que algumas células mais distantes da costa. Com a análise da tendência da série dos altímetros obteve-se uma elevação de $2,23 \mathrm{~mm} /$ ano para o período de 2007 a 2016.

A evolução temporal do DVB-I pode ser modelada a partir de longas séries temporais (mais de 5 anos) de dados da altimetria por satélite, observações GNSS e observações maregráficas. Estas informações estão em consonância com a visão para integração com o IHRS. Sendo assim, os resultados baseados na análise da posição geocêntrica do DVB-I com base em séries temporais GNSS, maregráficas e altimétricas da região do Datum Vertical Brasileiro de Imbituba evidenciaram uma taxa de elevação de $+2,24 \mathrm{~mm} /$ ano na região do Datum. Este valor está em concordância com informações globais de elevação do nível médio do mar. Ficou evidenciada a evolução do NMM na região do DVB-I pela determinação da variação temporal da posição geocêntrica do marégrafo associada com a análise dos dados maregráficos e altimétricos.

\section{Bibliografia}

Alencar, J.C.M. (1990). "Datum Altimétrico Brasileiro", Caderno de Geociências, no. 5, Rio de Janeiro, Brasil, pp. 69-73.

Alves, D.B.M.; Meneguette Jr, M.; Monico, J.F.G. (2005). "Utilizando spline cúbicas naturais para atenuação de erros no posicionamento GPS", Tend. Matemática Aplicada e Computacional, vol. 6, no. 2, pp. 197-205.

AVISO (2016). "Data: Mean Sea Level". Disponível em: $<$ http://www.aviso.altimetry.fr/en/data/products/oceanindicators-products/meansea-level.html>, acessado em 10/03/2018. 
Bouman, J.; Bosch, W. Goebel, G.; Müller, H.; Sánchez, L., Schmidt, M.; Sebera, J. (2010). "Das Schwerefeld der Erde-Messen, Darstellen und Auswerten", Fachbeitrag. Zeitschrift für Vermessungswesen, vol. 135, pp. 87-92.

Cordini, J. (1998). "Aspectos Geodinâmicos no Datum da Rede Altimétrica do SGB”, Tese de Doutorado, Curso de Pós-Graduação em Ciências Geodésicas, Universidade Federal do Paraná, 183 pp.

CSIRO Marine and Atmospheric Research (2018). "Sea Level Rise”. Disponível em: $<$ http://www.cmar.csiro.au/sealevel/>, acessado em 02/05/2018.

Dach, R. (2011). "Script RNX2SNX: RINEX TO SINEX”, Bernese 5.2.

Dach, R.; Lutz, S.; Walser, P.; Fridez, P. (2015). Bernese GNSS Software version 5.2, Astronomical Institute, University of Bern.

Dalazoana, R.; Luz, R.T.; Lima, S.R.S.; Miranda, Fr. A.; Palmeiro, A.S.; Miranda, Fa. A.; Freitas, S.R.C. (2005). "Controle Vertical das RRNN e da Posição Geocêntrica do Marégrafo no Porto de Imbituba”, IV Colóquio Brasileiro de Ciências Geodésicas, Curitiba, Brasiln Anais 18 a 20 de maio de 2005.

Dalazoana, R. (2006). "Estudos dirigidos à análise temporal do Datum Vertical Brasileiro", Tese de Doutorado, Curso de Pós-Graduação em Ciências Geodésicas, Universidade Federal do Paraná, 188 pp.

Dalazoana, R.; De Freitas, S.R.C. (2006). "Estudos Dirigidos à Análise Temporal do Datum Vertical Brasileiro", Boletim de Ciências Geodésicas: Resumos, vol. 12, no. 1, pp. 173-174.

Da Silva L.M. (2017). “Análise da Evolução Temporal do Datum Vertical Brasileiro de Imbituba”, Tese de Doutorado, Curso de Pós-Graduação em Ciências Geodésicas, Universidade Federal do Paraná, 270 pp.

Da Silva, L.M.; De Freitas, S.R.C. (2014). “Análise da Variação Temporal do Nível Médio do Mar nas Estações da RMPG”, Simpósio Sirgas, La Paz, Bolívia, Noviembre 24-26.

(2015). "Estimativa da posição atual do Datum Vertical Brasileiro de Imbituba a partir de dados maregráficos, observações GNSS e Altimetria por Satélites", Simpósio Sirgas, Santo Domingo, República Dominicana, Noviembro 1620.

Da Silva, L.M.; De Freitas, S.R.C.; Dalazoana, R. (2016). “Análise de Séries Temporais Maregráficas correlacionadas com observações GNSS do Datum Vertical Brasileiro de Imbituba-SC", Revista Brasileira de Cartografia, vol. 68, pp. 7390.

(2018). "Analysis of Dynamic Effects on the Brazilian Vertical Datum", IntechOpen Science: Sea Level Rise and Coastal Infrastructure: Yuanzhi Zhang, Yijun Hou and Xiaomei Yang, pp. 21-38, DOI: 10.5772/intechopen.71546. Available from: $<$ https://www.intechopen.com/books/sea-level-rise-and-coastalinfrastructure/analysis-of-dynamic-effects-on-the-brazilian-vertical-datum>. 
De Freitas, S.R.C.; Cordini, J.; Krueger, C.P.; Santos, M.C. (1998). "The Geocentric position of the Brazilian Vertical Datum", International Symposium on Marine Positioning: "United Nations Year of the Oceans", Florida Institute of Technology Melbourne, FL, USA, Proceedings of INSMAP98, pp. 230-240.

De Freitas, S.RC.; Medina, A.S.; Lima, S.R.S. (2002). “Associated Problems to link South American Vertical Networks and possible approaches to face them", IAG Symposia, vol. 124: Vertical Reference Systems; in: Drewes, H.; Dodson, A.H.; Fortes, L.P.S.; Sánchez, L.; Sandoval, P. (ed.), Springer, Berlin, pp. 318-323.

De Freitas, S.R.C. (2015). "SIRGAS-WGIII activities for unifying height systems in Latin America”, Revista Cartográfica, núm. 91, pp. 75-91.

Ferreira, V.G. (2008). “Análise da Componente Anômala do Geopotencial no Datum Vertical Brasileiro com base no sistema lagunar de Imauri, SC", Dissertação de Mestrado, Curso de Pós-Graduação em Ciências Geodésicas, Universidade Federal do Paraná, 116 pp.

GGOS (2018). "The Global Geodetic Observing System: Introducing GGOS - Additional Information: GGOS Components". Disponível em: <http://www.ggos.org/>, acessado em 12/05/2018.

Gregorius, T. (1996). Gipsy-Oasis II - How it works, Departament of Geomatics, University of Newcastle upon Tyne.

IAG (International Association of Geodesy) (2015). "IAG and IUGG Resolutions IAG Resolutions: Prague, Czech Republic 2015. Resolution $\mathrm{n}^{\circ} 1$ for the definition and realization of an International Height Reference System (IHRS)". Disponível em: <http://iag.dgfi.tum.de/fileadmin/IAG-docs/IAG_Resolutions_2015.pdf>, acessado em 02/05/2018.

IAG (2018). “IAG Office - IAG GGGOS”. Disponível em: < http://iag.dgfi.tum.de/index.php?id=253>, acessado em 05/03/2018.

IBGE (2011). Manual de Atividades, Centro de Processamento SIRGAS-IBGE.

(2013). "Relatório de Monitoramento da variação do Nível Médio do Mar nas Estações da Rede Maregráfica Permanente para Geodésia -2011-2012”, Rio de Janeiro, 46 pp.

(2016). “Análise do Nível Médio do Mar nas Estações da Rede Maregráfica Permanente para Geodésia - RMPG 2001/2015”, Rio de Janeiro, 65 pp.

(2018). "RMPG: Introdução". Disponível em: $<$ http://www.ibge.gov.br/home/ geociencias /geodesia /rmpg/rmpg.shtm?c=7>, acessado em 12/03/2018.

IERS (2018). “International VLBI Service for Geodesy and Astrometry”. Disponível em:

$<$ https:// www.iers.org/IERS/EN/Organization/TechniqueCentres/IVS/ivs.html>, acessado em 21/05/ 2018. 
Keysers, J.H.; Quadros, N.D.; Collier, P.A. (2013). Vertical Datum Transformations across the Littoral Zone. Report prepared for the Commonwealth Government of Australia, Department of Climate Change and Energy Efficiency, 110 pp.

Luz, R.T.; De Freitas, S.R.C.; Dalazoana, R. (2002). “Acompanhamento do Datum Altimétrico Imbituba através das Redes Altimétrica e Maregráfica do Sistema Geodésico Brasileiro", IAG Symposium, 2002, VII Congreso Internacional de Ciencias de la Tierra, Santiago-Chile.

Luz, R.T. (2008). "Estratégias para modernização da componente vertical do Sistema Geodésico Brasileiro e sua integração ao SIRGAS", Tese de Doutorado, Curso de Pós-Graduação em Ciências Geodésicas, Universidade Federal do Paraná, 228 pp.

Luz, R.T.; Bosch, W.; De Freitas, S.R.C.; Heck, B.; Dalazona, R. (2009). "Evaluating the Brazilian Vertical Datum Through Improved Coastal Satellite Altimetry Data". Michael Sideris (org.), IAG Series: Observing our Changing Earth. 1 ed., Berlin, Springer-Verlag, vol. 133, pp. 735-741.

Miranda, F.A. (2006). "Contribuição para a Análise do Campo da Gravidade na Região do Datum Vertical Brasileiro", Dissertação de Mestrado, Curso de Pós-Graduação em Ciências Geodésicas, Universidade Federal do Paraná, 89 pp.

NOAA (2016). "Laboratory for Satellite Altimetry/Sea Level Rise: Global sea level times series". Disponível em:

$<$ http://www.star.nesdis.noaa.gov/sod/lsa/SeaLevelRise/LSA_SLR_timeseries_ global.php>, acessado em 11/05/2018.

Palmeiro, A.S. (2011). "Análise do Vínculo do Datum Vertical Brasileiro a um Sistema Global de Altitudes com Base em Soluções Fixadas e Livres do PVCG", Tese de Doutorado, Curso de Pós-Graduação em Ciências Geodésicas, Universidade Federal do Paraná, 159 pp.

Palmeiro, A.S.; De Freitas, S.R.C.; Dalazona, R. (2013). "Análise do vínculo do Datum Vertical Brasileiro a um Sistema Global de Altitudes", Revista Brasileira de Cartografia, nos. 65-66, p. 1097-1111.

Sánchez, L.; Dayoub, N.; Čunderlík, R.; Minarechová, Z.; Mikula, K.; Vatrt, V.; Vojtíšková, M.; Šíma, Z. (2012). "W0 Estimates in the Frame of the GGOS Working Group on Vertical Datum Standardisation", Series International Association of Geodesy Symposia: Springer. Chapter: Gravity, Geoid and Height Systems, vol. 141, pp. 203-210.

Smith, J.; Wigginton, N.; Ash, C.; Fahrenkamp-Uppenbrink, J.; Pennisi, E. (2010). "Changing Oceans: Introduction to Special ISSUE", Science, vol. 328, pp. 1497. DOI: $10.1126 /$ science.328.5985.1497. 